\title{
The comparative evaluation of apoptosis produced by leuprolide or orchiectomy on rat prostate tissue
}

\author{
Basri Cakiroglu ${ }^{1}$, Aydin Ismet Hazar ${ }^{2}$, Seyit Erkan Eyyupoglu ${ }^{3}$, Mustafa Bahadir Can Balci ${ }^{2}$, \\ Orhun Sinanoglu ${ }^{4}$, Pinar Tuzlali ${ }^{5}$ \\ ${ }^{1}$ Department of Urology, Hisar Intercontinental Hospital, Istanbul, Turkey; \\ ${ }^{2}$ Department of Urology, Taksim Training and Research Hospital, Istanbul, Turkey; \\ ${ }^{3}$ Department of Urology, Amasya Training and Research Hospital, Amasya, Turkey; \\ ${ }^{4}$ Department of Urology, Maltepe University Medical School, Istanbul, Turkey; \\ ${ }^{5}$ Department of Pathology, Taksim Training and Research Hospital, Istanbul, Turkey.
}

\begin{abstract}
Summary Introduction: Organisms are constantly in a balance meaning that while new cells are produced, some of the older ones die which takes place in 2 ways: necrosis or apoptosis. Apoptosis is the programmed cellular death triggered by intrinsic or extrinsic stimuli. In this study we have evaluated the apoptosis of prostate tissue generated by surgical or medical orchiectomy.

Material and Method: In this experimental study, we used 36 adult male rats that were evaluated in 3 groups. The first group (Group 1) consisted of 12 rats that had bilateral orchiectomy; the second group (Group 2) included 12 rats that were given leuprolide acetate and the third group (Group 3) consisted of 12 control rats. Immunohistochemical staining of the prostate of all rats was performed and the presence of glandular atrophy and apoptosis were evaluated in the three groups. The statistical differences between the two groups were evaluated by the Fisher exact test.

Results: Glandular atrophy was not determined in any rat of the control group, and the apoptotic staining was in the normal limits in all the control rats. In Leuprolide group, glandular atrophy was mild in 7 cases, and moderate in 3 rats. In 2 rats of the Leuprolide group, atrophy was not demonstrated. In surgical orchiectomy group, glandular atrophy was present in all cases. Atrophy was observed as cystic atrophy. Statistical analysis with the Fisher exact test revealed that glandular atrophy was statistically significantly more common in surgical orchiectomy group compared with Leuprolide group $(p=0,012)$.

Conclusion: If the aim of treatment in androgen dependent prostatic adenocarcinoma or benign prostate hypertrophy is the construction of a robust apoptosis, bilateral orchiectomy generates a more powerful apoptosis compared with Leuprolide.
\end{abstract}

KEY WORDS: Prostate; Orchiectomy; Leuprolide; Apoptosis.

Submitted 18 June 2015; Accepted 15 September 2015

\section{INTRODUCTION}

Prostate is the organ most commonly affected by malign lesions in males and prostate cancer is the second most common cause of death in men in many countries (1). Organisms are constantly in a quite equilibrium. While new cells are produced, some of the existing cells are taken away by cellular death in order to preserve this balance. The cellular death has two modalities: apoptosis and necrosis $(2,3)$. In both of them, cellular death takes place at the end of the regular, consecutive biochemical and morphological events (4). Necrosis may be defined as the death of cells before their appropriate time. The period after the exposure of cells to any chemical or physical agent that may damage the cellular plasma membrane is defined as the necrosis. Necrosis takes place as a result of acute, non-physiological cellular injury and it is the pathological form of cellular death $(5,6)$. Cellular necrosis is characterized by cellular ballooning, ballooning of organelles, budding of cellular membrane and increase in cellular permeability. Commonly karyolysis accompanies necrosis and DNA breakages are present in a non-specific way (7). On the other hand, apoptosis is the programmed cellular death triggered by intrinsic and extrinsic stimulants $(3,5,6,8)$. Conversely to necrosis, apoptosis develops in normal physiologic conditions and it is a physiological period of the cell. Apoptosis starts with the embryological development and continues through the whole life. Normal development and hemostasis of multicellular organisms are regulated by apoptosis. If there is no more need for the cells or the cells are damaged, they are eliminated with the apoptosis (9).

Apoptosis is an important biological period not only during the normal cellular physiology but also in benign and malign disease conditions. Understanding the exact cause triggering apoptosis will be the basis of many therapeutic strategies. According to the cellular kinetic studies, neoplastic prostate enlargement depends on the loss of balance between cellular proliferation and apoptosis $(10,11)$. In benign prostate hypertrophy (BPH) normal growth control mechanisms are not in process. Probably the reason is the overexpression of bcl-2 which is a potent apoptosis inhibitor originating from prostate glandular cells and basal cells of the old gland during hypertrophic proliferation $(12,13)$. This hypothesis is at the basis of potential molecular mechanism that protects long-living cells from self-destruction as in the case of prostate epithelial cells $(13,14)$. Bcl-2-mediated, mito-

No conflict of interest declared. 
chondria associated cell survival pathway (intrinsic pathway) is one of the major pathways that are targeted for inducing apoptosis in cancer cells. In addition to this, another major pathway that promotes apoptosis in cancer cells is the death receptor-mediated pathway (extrinsic pathway) (15). In this study we have evaluated the apoptosis of prostate tissue triggered by surgical or medical orchiectomy. For this reason, bilateral orchiectomy was performed in a group of rats and LH-RH analogues were given to the other group; the apoptosis was determined by immunohistochemical staining and compared between the two groups.

\section{MATERIALS AND METHODS}

In this experimental study, we used 36 adult male rats (Sprague Dawley) with an average of 250 gr weight and 10 weeks of age that were divided in 3 groups. The first group (Group 1) consisted of 12 rats that had bilateral orchiectomy; the second group (Group 2) included 12 rats that were given Leuprolide acetate and the third group (Group 3) consisted of 12 control rats. In the rats of the first group, after the intraperitoneal anesthesia of $25 \mathrm{mg} / \mathrm{kg}$ Pentothal, bilateral orchiectomy was performed, through an incision of the scrotum on the raphe, the cord was tightened with $4 / 0$ vicryl, the bleedings were cauterized and the skin was closed with 4/0 rapid vicryl. Single dose depot Leuprolide acetate was administered to the rats in the second group. The third group was regarded as the control group in which no intervention was performed. After 4 weeks, the rats were sacrificed after the injection of $100 \mathrm{mg} / \mathrm{kg}$ pentothal and bladder, prostate, vesicula seminalis and penis were taken en bloc, and put in formaldehyde.

\section{Histopathology}

Prostate glands were put on PBS and cut longitudinally; then they were fixed with tamponed formalin, embedded on paraffin and slices were obtained. All slices were investigated for the presence of inflammatory infiltration, edema, fibrosis, basal cell degeneration, hyperplasia, endothelial cellular volume density.

\section{Immunohistochemical Staining}

The material used for the staining was Bax:B-9 rat monoclonal IgG2b antibody. Bax protein eliminates the apoptosis by inhibiting the effects of Bcl-2 gene in cells and accelerates apoptotic cellular death Bax antibody attaches to the bax protein that has an increased concentration in cases with accelerated apoptosis. At the beginning of the procedure, the tissue slices were cleaned from the paraffin; incubated for 15 minutes in hydrogen peroxide solution and washed 2 times with TBS. A citrate tampon was produced on microwave oven and cooled at room temperature for 20 minutes and the slices were washed with TBS for 4 times. To prevent non-specific background staining, Ultra V Block (protein blockage) was performed at room temperature for 5 minutes. Without washing, only Ultra V Block on the lam was transferred. Bax antibody was dripped to cover the tissue and incubated for 1 hour, then diluted with water at a 1/100 ratio and washed with PBS for 4 times. We waited for twenty minutes after dripping Biotinylated Goat Antipolyvalent Solution (link yellow) serum and then we washed with PBS for 4 times and incubated until colored with AEC chromogen. Preparation of AEC was obtained by dripping 1 drop chromogen into $1 \mathrm{ml}$ substrate and washing with distilled water. Then, we counter-stained with Mayer's Hematoxylin and waited for 1 minute at most; finally we washed with distilled water and closed with Ultramount. Slices were investigated under light microscopy. Bax (+) staining demonstrates granular staining in cytoplasm. Increase in staining strength was recorded as $(+)$, strong increase was recorded as $(++)$ and normal staining was shown as $(\mathrm{N})$. Arithmetical decrease in glandular component, cystic formation, flattening in epithelium are regarded as the signs of atrophy and recorded as mild $(+)$, moderate $(++)$ and severe $(+++)$ atrophy (Table 4).

The statistical differences of the results between the two groups were evaluated by Fisher exact test.

\section{RESULTS}

After immunohistochemical staining, all the three groups were evaluated for glandular atrophy and apoptosis in general and the results are summarized in Table 1.

In 12 rats of control group glandular atrophy was not reported (Figure 1) and apoptotic staining was in the normal limits (Figure 2). In the Leuprolide group, glandular atrophy was mild (+) in 7 cases, and moderate $(++)$ in 3 rats. In 2 rats of the Leuprolide group, atrophy was not demonstrated. In surgical orchiectomy group; glandular atrophy was present in all cases. The atrophy was
Table 1.

The evaluation of glandular atrophy and apoptosis in prostates of Leuprolide, bilateral orchiectomy and control rat groups. Atrophy is evaluated as absent $(-)$, mild atrophy (+), moderate atrophy (++), severe atrophy (+++). Apoptosis is evaluated as; Bax staining normal $(N)$ (atrophy is not present), increase in staining (+), strong increase in staining (++).

\begin{tabular}{|c|c|c|c|c|c|c|}
\hline \multirow[b]{2}{*}{ Cases } & \multicolumn{2}{|c|}{ Control } & \multicolumn{2}{|c|}{ Bilateral orchiectomy } & \multicolumn{2}{|c|}{ Leuprolide } \\
\hline & Glandular atrophy & Apoptosis & Glandular atrophy & Apoptosis & Glandular atrophy & Apoptosis \\
\hline 1 & - & $\mathrm{N}$ & ++ & ++ & + & + \\
\hline 2 & - & $\mathrm{N}$ & ++ & + & ++ & ++ \\
\hline 3 & - & $\mathrm{N}$ & + & ++ & + & + \\
\hline 4 & - & $\mathrm{N}$ & + & + & + & + \\
\hline 5 & - & $\mathrm{N}$ & ++ & + & - & $\mathrm{N}$ \\
\hline 6 & - & $\mathrm{N}$ & + & + & + & + \\
\hline 7 & - & $\mathrm{N}$ & + & ++ & + & + \\
\hline 8 & - & $\mathrm{N}$ & + & ++ & - & $\mathrm{N}$ \\
\hline 9 & - & $\mathrm{N}$ & + & ++ & + & + \\
\hline 10 & - & $\mathrm{N}$ & + & ++ & + & + \\
\hline 11 & - & $\mathrm{N}$ & + & ++ & ++ & ++ \\
\hline 12 & - & $\mathrm{N}$ & + & ++ & ++ & ++ \\
\hline
\end{tabular}


Figure 1.

Glandular atrophy.

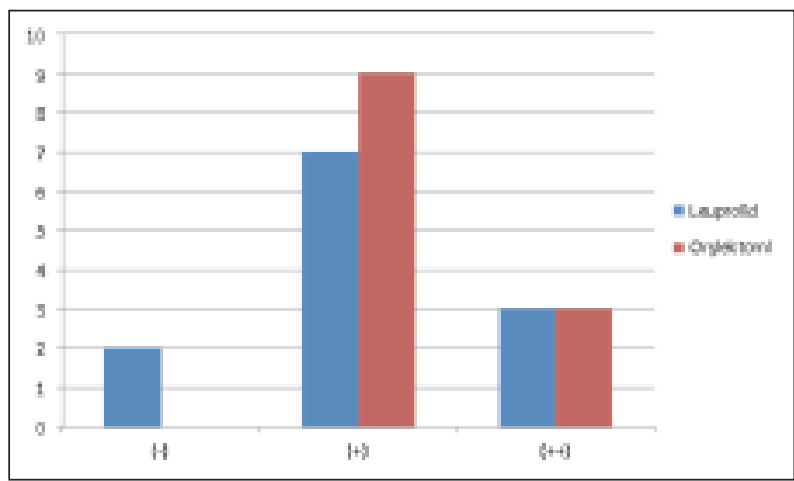

Figure 2.

Apoptotic staining.

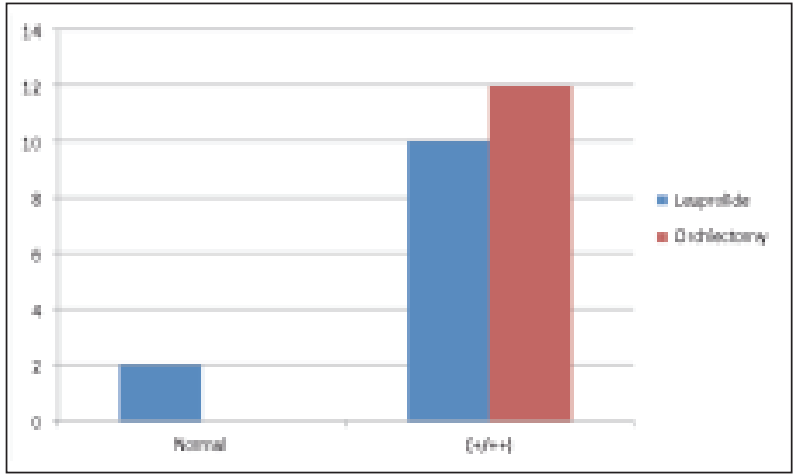

observed as cystic atrophy. In 9 rats of the orchiectomy group, glandular atrophy was mild $(+)$ and in 3 cases moderate $(++)$ glandular atrophy was present. In this group, apoptotic staining was increased mildly in 4 cases and moderately in 8 cases. Glandular atrophy was not present in 2 cases of the Leuprolide group (2/12, 16.6\%) and in this group statistically significant glandular atrophy was present (Fisher exact test $<0.001$ ). The statistical analysis with Fisher exact test revealed that glandular atrophy was statistically significantly more common in surgical orchiectomy group compared with Leuprolide group ( $p=0.012)$.

In the evaluation of apoptosis, in the 12 Leuprolide acetate administered rats, normal apoptotic staining was present in 2 rats $(2 / 12,16,6 \%)$, while apoptotic staining was increased in 5 rats $(5 / 12,41.6 \%)$ and apoptotic staining was strongly increased in the other 5 rats $(5 / 12$, 41.6\%). Statistically significant apoptotic staining was also reported in this group (Fisher Exact Test $<0.001$ ). In 12 rats with bilateral orchiectomy, normal apoptotic staining was not reported in any rat, while apoptotic staining was increased in 4 rats $(4 / 12,33,3 \%)$ and apoptotic staining was strongly increased in the other 8 rats (8/12, 66,6\%).

Statistically significant apoptotic staining was also reported in this group (Fisher exact test $<0.001$ ). In the orchiectomy group, apoptotic staining was statistically significantly more strong and more distinct compared with the Leuprolide group (Fisher exact test $<0.001$ ).
In atrophic cases apoptosis increases and this increase is in parallel with the density of atrophy. The drug produced 83.3\% atrophy (more commonly mild) but severe atrophy was not observed in the drug group. Atrophy was as a decrease in glands sometimes together with periductal fibrosis but occasionally it was cystic in structure.

\section{Discussion}

In this study, we evaluated the apoptotic changes in prostates of castrated rats and Leuprolide administered rats. In atrophic prostates increase in apoptosis and a direct correlation of this increase with the density of atrophy were observed. We demonstrated that in Leuprolide administered group, atrophy developed in $83.3 \%$ of the cases and the atrophy was mild; on the other hand in orchiectomy group atrophy was 100\% and the atrophy was predominantly moderate. In both groups, together with the atrophy, in some cases periductal fibrosis or formation of cystic structures were observed.

Though many studies were performed, new substances or more rational drug combinations are still required in limiting growth of androgen resistant prostate cancer cells. Increasing evidences support the role of protein kinases and anti-apoptotic signal cascades in therapeutic resistance of castration resistant prostate cancer $(16,17)$. An antiapoptotic signal with hyperactive PI3K pathway was suggested to be the probable cause of resistance to treatment in prostate cancer cells (18).

Owing to the dependence of $\mathrm{BPH}$ and prostate cancer to the androgen steroids, these diseases became the model for studies of apoptosis of the prostate. Apoptosis, a decrease in cellular proliferation, is one of the main mechanisms causing prostate depletion in androgen deficient conditions.

Ten days after castration, rat prostate ventral tissue regresses completely and prostate androgen dependent epithelial cells degenerate with a ratio of $80 \%$ (19).

The normal growth and hemostasis of multicellular organisms are regulated with apoptosis. Prostate glandular epithelial cells are separated from basal lamina by interglandular stroma composed of smooth muscle cells and fibroblasts. In adult prostate, glands and ducts are arranged as double layered by luminal and basal epithelial cells. Basal cell layer, that is suggested to contain prostatic stem cells giving rise to both basal and luminal epithelial cells, is reproduced in castrated mice after testosterone replacement $(20,22)$. After castration, depletion in prostate gland results in apoptosis of luminal cells and approximately $80 \%$ of epithelial cells die (23). The glandular atrophy is not complete, and rudimentary glandular structures are observed for a long time after castration (24). Androgen deprivation due to castration stimulates apoptosis in human prostate tissue. The apoptotic response in human prostate tissue is less than that of the rat ventral prostate. In the first day after castration, the percentage of TUNEL (+) cells (apoptotic index) increases, reaching to a maximum level at the fourth day after castration and then the apoptotic index progressively decreases (25). The ventral prostate of rat is a good model for in vivo apoptosis; prostate epithelial cells become independent to androgenic steroids when they are cultured (26). In 
sensitive Dunning R3327PAP rat prostate adenocarcino$\mathrm{ma}$, after castration tumor volume and epithelial stromal cells were reported to be stable, however when 50 microgram estradiol benzoate was added to the castration total tumor volume was reported to be decreased and tumor cells died (27). In BPH development, normal adult prostate enlarges unusually. In $\mathrm{BPH}$, tissue proliferative/ apoptotic balance is deteriorated in the favor of proliferation in both epithelial and stromal cells. Endogenous apoptosis ratios are significantly decreased in BPH (28, 29). This decreased apoptotic activity in human BPH samples, reflects the activity of antiapoptotic protein Bcl-2 in epithelial cells of these tissues (30).

In $\mathrm{BPH}$, morphological induction of apoptosis as a response to doxazosin in prostatic stromal smooth muscle cells was reported. In pre-treatment biopsies of patients with BPH, any apoptotic cells were not observed with terminal transferase end labeling. With 3 months of doxazosin treatment, a dramatic apoptosis induction was observed in those patients in smooth muscle cells with terminal transferase end labeling (31).

Increase in cell number in $\mathrm{BPH}$ and prostate carcinoma depends on the decrease in apoptotic cellular death. The administration of alpha adrenergic antagonists decreases the surgical treatment requirements in BPH. Moreover, they reduce the tonus of bladder neck and these agents change the course of the disease by inducing apoptosis. Terazosin causes apoptosis in prostate epithelium in a dose dependent manner (32). In rat ventral prostate, 5-alpha reductase inhibition also results in apoptosis but apoptosis caused by castration is more marked. While $60 \%$ cellular decrease is observed on the $9^{\text {th }}$ day with finasteride, castration results in 90\% decrease of cells (33).

Cardillo et al. investigated 26 patients who were hormonally ablated with LH-RH analogues for one month before radical prostatectomy. They compared the apoptosis in pretreatment biopsy and radical prostatectomy materials. They observed that after androgen deprivation apoptosis was present in normal prostatic epithelial cells and prostate cancer cells (34).

\section{Conclusion}

If the aim of treatment in androgen dependent prostatic adenocarcinoma or benign prostate hypertrophy is construction of robust apoptosis, bilateral orchiectomy generates more powerful apoptosis compared with Leuprolide. In Leuprolide administered cases, apoptosis was observed with a ratio of $83.3 \%$.

\section{AUthORS' CONTRIBUtions}

BC, SEE and AIH and conducted the experiments and participated in acquisition, analysis, and interpretation of data. BC, SEE and MBCB participated in analysis and interpretation of data, and drafted the manuscript. OS helped in analyzing the data and in drafting the manuscript. PT drew the study conception and design, critically participated in revising the manuscript for important intellectual content and has given the final approval of the version to be submitted. All authors read and approved the final manuscript.

\section{ACKNOWLedGement}

We thank Pathology Laboratory, Taksim Training and Research Hospital for laboratory facilities, technical assistance and financial aid.

\section{References}

1. Ellison LF, Wilkins K. Cancer prevalence in the Canadian population. Health Rep. 2009; 20:7-19.

2. Ameisen JS:The origin of programmed cell death. Science 1996; 272:1278.

3. Thompson CB. Apoptosis in the pathogenesis and treatment of disease. Science. 1995; 267:1456.

4. Kiess W, Gallaher B. Hormonal control of programed cell death/apoptosis. Eur J. Endocrin 1998; 18:482.

5. Hetts SW. To die or not to die:An overview of apoptosis and its role in disease. JAMA 1998; 278:300.

6. Majno G, Joris I. Apoptosis, Oncosis and Necrosis:An overview of cell death.Am J Pathol. 1995; 146:3.

7. Van Furth R, Van Zwet TL. Immunucytochemical detection of 5bromo-2-deoxyuridine incorporation in individual cells. J Immunol Methods. 1988; 108:45

8. Kerr JFR, Wyllie AH, Currie AR. Apoptosis: a basic biological phenomenon with wide-ranging implications in tissue kinetics. $\mathrm{Br} J$ Cancer. 1972; 26:239-257.

9. Kerr JF. Shrinkage necrosis: A distinct mode of cellular death. J Pathol. 1971; 105;13.

10. Caine M, Pfau A, Perlberg S. The use of alpha-adrenergic blockers in benign prostatic obstruction. Br J Urol. 1976; 48,255.

11. McConnell JD. Medical management of benign prostatic hyperplasia with androgen suppression. Prostate. 1990; suppl. 3:49.

12. Lepor $\mathrm{H}$. Role of long-acting selective alpha-1 blodkers in the treatment of benign prostatic hyperplasia. Urol Clin North Amer. 1990; 17:651.

13. Gormey GC, McConnell JD, Stoner E, et al. The effect of finasteride in men with benign prostatic hyperplasia. The Finasteride Study Group. New Engl J Med. 1992; 327:1185.

14. Peter CA, Walsh PC. The effect of nafarelin acetate, a luteinizing-hormone-releasing hormone agonist, on benign prostatic hyperplasia. New Engl J Med. 1987; 317:559.

15. Fulda S, Debatin KM: 5-Aza-20-deoxycytidine and IFN-gamma cooperate to sensitize for TRAIL-induced apoptosis by upregulating caspase-8. Oncogene. 2006; 25:5125-5133.

16. Loriot Y, Massard C, Fizazi K. Recent developments in treatments targeting castration-resistant prostate cancer bone metastases. Ann Oncol. 2012; 23:1085-1094.

17. Fizazi KS, Higano CS, Nelson JB, et al. Phase III, randomized, placebo-controlled study of docetaxel in combination with zibotentan in patients with metastatic castration-resistant prostate cancer. J Clin Oncol. 2013; 31:1740-1747.

18. Bitting RL, Armstrong AJ. Targeting the PI3K/Akt/mTOR pathway in castration-resistant prostate cancer. Endocr Relat Cancer. 2013; 20:R83-R99.

19. Kyprianou N, Isaacs JT. Activation of programmed cell death in the rate ventral prostate after castration. Endocrinology. 1988; 122:552-562. 
20. Blendy JA, Kaestner KH, Weinbauer GF, et al. Severe impairment of spermatogenesis in mice lacking the CREM gene. Nature. 1996; 380:162-5.

21. Overbeeke R, Steffens-Nakken H, Vermes I, et al. Early features of apoptosis detected by four different flow cytometry assays. Apoptosis. 1998; 3:115-21.

22. Ellis RE, Yuan JY, Horvitz HR. Mechanisms and functions of cell death.Annu Rev Cell Biol. 1991; 7:663-98.

23-Yuan JY, Shao ZF. Simple model of image formation by scanning tunneling microscopy of non-conducting materials. Ultramicroscopy. 1990; 34:223-6.

24. Hengartner MO, Ellis RE, Horvitz RH. Caenorhabditis elegansgene Ced-9 protects cell from programmed cell deaht. Nature. 1992; 356:494.

25. Alnemri ES, Livington DJ, Nicholson DW, et al. Human ICE/CED-3 protease nomenclature Cell 1996; 87;171.

26. Miura $M$, Zhu $H$, Rotello $R$, et al. Induction of apoptosis in fibroblasts by IL-1B-converting enzyme, a mammalian homologof the C.Elegans cell deaht gene Ced-3. Cell. 1993; 75:653.

27. Raff M. Cell suicide for beginners. Nature. 1998; 396:119.
28. Raff M. Social controls on cell survival and cell deaht. Nature 1992; 356:397.

29. Liu X, Kim CN, Yang J, et al. Induction of apoptotic program in cell-free extracts: requirement for dATP and cytochrome $c$. Cell. 1996; 86:147-57.

30. Reed JC. Bcl-2 family proteins. Oncogene. 1998; 17:3225-36.

31. Kroemer $G$. The proto-oncogene Bcl-2 and its role in regulating apoptosis. Nat Med. 1997; 3:614-620.

32. Bates S, Vousden KH. p53 in signaling checkpoint arrest or apoptosis.Curr Opin Genetics Develop. 1996; 6:12-18.

33. Krammer PH,Dhein J,Walczak H.The role of APO-1 mediated apoptosis in the immune system. Immun Rev. 1994; 142;175-191.

34. Villa P, Kaufman SH, Earnshaw WC. Caspases and caspase inhibitors. Trends Biochem Sci. 1997; 22:388-393.

\section{Ethical Code}

Bagcilar Training and Research Hospital, Etics Committee of Clinical Research No.8/04.10.2014

\section{Correspondence}

Basri Cakiroglu, MD (Corresponding Author)

drbasri@hotmail.com

Department of Urology Hisar Intercontinental Hospital Department of Urology Saray Mah. Siteyolu Cad. No:7 34768 Umraniye, Istanbul, Turkey

Aydin Ismet Hazar, MD

Mustafa Bahadir Can Balci, MD

Department of Urology, Taksim Training and Research Hospital Istanbul, Turkey

Seyit Erkan Eyyupoglu, MD

Department of Urology, Amasya Training and Research Hospital Istanbul, Turkey

Orhun Sinanoglu, MD

Department of Urology, Maltepe University Medical School, Istanbul, Turkey

Pinar Tuzlali, MD

Department of Pathology, Taksim Training and Research Hospital, Istanbul, Turkey 